\title{
Volatility Modeling of Emerging Foreign Exchange Market: A Case of Bangladesh
}

\author{
Laila Arjuman Ara*, Mohammad Masudur Rahman ${ }^{* *}$
}

\begin{abstract}
This paper examined the volatility models for exchange rate return, including Random Walk model, AR model, GARCH model and extensive GARCH model, with Normal and Student-t distribution assumption as well as nonparametric specification test of these models. We fit these models to Bangladesh foreign exchange rate index from January 1999 to December 31, 2012. The return series of Bangladesh foreign exchange rate are leptokurtic, significant skewness, deviation from normality as well as the returns series are volatility clustering as well. We found that student $t$ distribution into GARCH model improves the better performance to forecast the volatility for Bangladesh foreign exchange market. The traditional likelihood comparison showed that the importance of GARCH model in modeling of Bangladesh foreign market, but the modern nonparametric specification test found that $R W, A R$ and the model with GARCH effect are still grossly mis-specified. All these imply that there is still a long way before we reach the adequate specification for Bangladesh exchange rate dynamics.
\end{abstract}

Keywords: Exchange Rate Volatility; GARCH; Emerging Market;

* Associate Professor, School of Business Studies Southeast University, Dhaka, Bangladesh Email: lailamolly2003@yahoo.com, Tel: 88-01715218495

** Research Fellow, Bangladesh Foreign Trade Institute, TCB Building, 1 Karwan Bazar, Dhaka, Bangladesh, Email: masudbfti@gmail.com 


\section{Introduction:}

Volatility plays a key role in asset and portfolio management, derivatives pricing as well as exchange rate forecasting. Accurate measures and good forecasts of volatility are crucial for the implementation and evaluation trading and hedging strategies in foreign exchange market. Volatility also affects greatly on investing and financing decisionmaking, consumer behavior as well. Therefore, estimation and forecasting volatility of foreign exchange rate is being the focus research topic on international finance.

Bangladesh has been following the freely floating exchange rate system from May 30, 2003 and we experienced that freely floating exchange rate system less or more volatile, so it is important to forecast the volatility of exchange rate. The main objective of the study is to find out the best performing model for estimating volatility of Bangladesh foreign exchange market using nonparametric specification test. The plan of this paper is as follows. Following the introduction in section 1, the methodology is in next section. Section 3 deals with data and descriptive statistics, in sample performance discuss in the section 4, the section 5 covers with the nonparametric specification test for all the models and conclusion are given in the final section.

\section{Methodology:}

To identify the best performing exchange rate volatility model for Bangladesh foreign exchange market, we used, (1) Random Walk (RW) model 2) Autoregressive Moving Average (ARMA) model (3) Generalized Autoregressive Conditional Heteroskedasticity (GARCH) model (4) Extensive GARCH model and (5) nonparametric specification test of these models.

\subsection{Random Walk Model:}

The random walk model was put forward first by the Samuelson (1965) at the earliest stage, he believed that price is decided by the actual value of the interest on shares to convert into cash, that's present appearance is random walk. In this research we assumed that return series of foreign exchange rate is $\left\{r_{t}\right\}$, random walk model as follows process:

$$
r_{t}=u+\varepsilon_{t}
$$


Where $u$ is the model's parameter, $E\left(\varepsilon_{t}\right)=0, \operatorname{Var}\left(\varepsilon_{t}\right) \sigma^{2}$ and $\varepsilon_{t}$ to follow a normal distribution.

\subsection{ARMA Model:}

The ARMA (the Autoregressive Moving Average) model is a kind of model that describes the sequence relativity. Proposed by the Box\& Jenkins (1970) first, they thought that single value consisting of sequence has the uncertainty, but from the whole variation of sequence there is certain regulation, which is usually used for short-term estimate of time sequence. If the series $\left\{r_{t}\right\}$ satisfies $\operatorname{ARMA}(p, q)$, then $\left\{r_{t}\right\}$ can be described as follows basic form:

$$
r_{t}=\mu+\sum_{i=1}^{p} \Phi_{i} r_{t-1}+\sum_{j=1}^{q} \xi_{j} \varepsilon_{t-j}+\varepsilon_{t}
$$

Where, $\Phi_{i}, \xi_{i}, i=1 \cdots p$ is a parameter, $E\left(\varepsilon_{t}\right)=0, \operatorname{Var}\left(\varepsilon_{t}\right)=\sigma^{2}$ and $\varepsilon_{t}$ to match a certain particular distribution.

\subsection{GARCH Model:}

The conditional variance of $\varepsilon_{t}$ is assume constant for random walk and AR model. Nevertheless, in financial time series data, $\varepsilon_{t}$ the conditional volatility changes over time. The exchange rate return series is $\left\{r_{t}\right\}$, simple $\operatorname{GARCH}(p, q)$ model can be described as the follow form:

$$
\left\{\begin{array}{l}
r_{t}=u+\varepsilon_{t} \\
E\left(\varepsilon_{t} \mid I_{t-1}\right)=0, E\left(\varepsilon_{t}^{2} \mid I_{t-1}\right)=h_{t} \\
h_{t}=\alpha+\sum_{j=1}^{q} \alpha_{j} \varepsilon_{t-j}^{2}+\sum_{i=1}^{p} \beta_{i} h_{t-1}
\end{array}\right.
$$

Where, $I_{t-1}$ is the assembly of all information on $t-1, \alpha, \alpha_{i}>0, i=1, \cdots q$; $\beta_{i}>0, i=1, \cdots p$

The GARCH-mean (GARCH-M) reflecting the presence of conditional variance in the conditional mean. If we convert regress coefficient in the $\operatorname{GRACH}(p, q)$ model to 
$r_{t}=u+\delta \sqrt{h}+\varepsilon_{t}$ on the basis of the simple $\operatorname{GRACH}(p, q)$ model, then the model changes into $\operatorname{GRACH}(p, q)-M$ model, which is used to catch the phenomenon that the change of conditional variance in pace with time, may cause the change of conditional of mean pace in time. The GARCH-M model is a natural extension of GARCH model, since it introduces conditional variance or standard deviation.

\subsection{Expanded GARCH:}

It may be modeled by the asymmetric volatility model or threshold ARCH (or TGARCH) model in which a multiplicative "indicator" dummy variables in introduced to the capture the influence of the sign of exchange return on the conditional variance. In addition, Asymmetric model includes EGARCH model, TGARCH model, etc. This paper chooses TGARCH model in Asymmetric model for discussion only. To explain the lever effect of volatility, we can change the volatility equation in simple $G R A C H(p, q)$ model into

$$
h_{t}=\alpha+\sum_{j=1}^{q} \alpha_{j} \varepsilon_{t-j}^{2}+\phi \varepsilon_{t-1}^{2} d_{t-1}+\sum_{i=1}^{p} \beta_{i} h_{t-1}
$$

Where, $d_{t}$ is a dummy variable $d_{t}=\left\{\begin{array}{l}1, \varepsilon_{t}<0 \\ 0 \text { Otherwise }\end{array}\right.$, then the model changes into the TGARCH model. IGARCH a kind of infinite variance model in GARCH branch model, it suppose that the volatility is satisfied with the equation that

$$
h_{t}=\alpha+\lambda \varepsilon_{t-1}^{2}+(1-\lambda) h_{t-1}
$$

Among them, $0 \leq \lambda \leq 1$. When $\alpha=0$, IGARCH Model equals to an infinite index shift average model, that is,

$$
h_{t}=(1-\lambda) \sum_{i=1}^{\infty} \lambda^{i} \varepsilon_{t-i}^{2}
$$

\subsection{Non-normal Error Distribution (T-distribution):}

The assumption for error distribution is the foundation of the maximum likelihood estimation to the model. Usually we suppose the error follows the normal distribution. 
However, the assumption of normal distribution for excess kurtosis and fat tail of financial series return may gives error result of the model. Therefore, we should add some fat tail to describe the characteristic of financial data. Non-normal error distribution that we choose in this paper is t distribution. The $\mathrm{t}$ distribution's density function is :

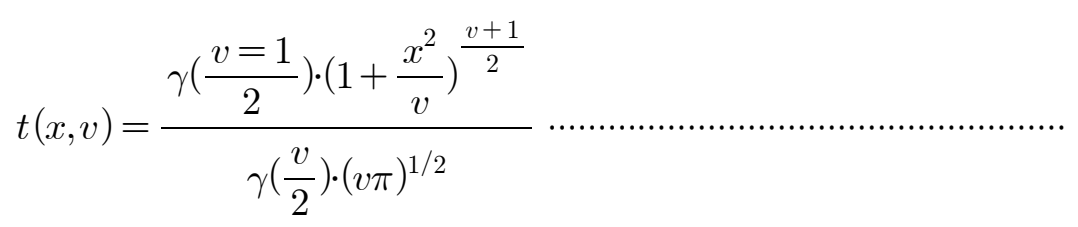

here, $v$ is the degree of freedom ; $\gamma(\cdot)$ is Gamma function.

\section{6 nonparametric Evaluation Method:}

Recently Hong and $\mathrm{Li}$ (2005) proposed two new nonparametric transition density-based specification tests for continuous-time models. These tests share the appealing features of both Ait-Sahalia (1996) and Gallant and Tauchen(1996) nonparametric approaches and have many additional nice properties. Such as

- Unlike Ait-Sahalia (1996) marginal density-based test, the tests are based on the transition density, which captures the full dynamics of a continuous-time process.

- To achieve robustness to persistent dependence, the data is transformed via a dynamic probability integral transform using the model transition density, which is well known in statistics and is more recently used to evaluate out-of-sample density forecasts in discrete-time analysis (e.g., Diebold, Gunther and Tay 1998, Hong, Li and Zhao 2004). The transformed sequence is i.i.d. U[0, 1] under correct model specification, irrespective of the dependence structure of the original data.

- To eliminate the well-known "boundary bias" of kernel estimators, a boundary -modified kernel is introduced.

- To reduce the impact of parameter estimation uncertainty, a test based on the Hollinger metric is proposed.

- The regularity conditions for asymptotic analysis are based on the model transition density rather than the stochastic differential equation of the underlying process. As a consequence, the tests are applicable to a vast variety of continuous-time and discrete-time dynamic models, such as GARCH/stochastic volatility models, regime-switching models, jump-diffusion models and multi-factor diffusion models. 
This research uses the nonparametric tests proposed recently by Hong and $\mathrm{Li}(2005)$ to evaluate different volatility rate models. Assuming the underlying process $\left\{X_{t}\right\}$ follows the following data generating process:

$$
d X_{t}=\mu_{0}\left(X_{t}, t\right) d t+\sigma_{0}\left(X_{t}, t\right) d W_{t}
$$

Where $\mu_{0}\left(X_{t}, t\right)$ and $\sigma_{0}\left(X_{t}, t\right)$ are the drift and diffusion functions respectively and is $W_{t}$ a standard Brownian motion. Let $p_{0}(x, t / y, s)$ be the true transition density of the diffusion process $\left\{X_{t}\right\}$, that is the conditional density of $X_{t}=x$ given, $X_{s}=y, s<t$. For a given pair of drift and diffusion models $\mu\left(X_{t}, t, \theta\right)$ and $\sigma\left(X_{t}, t, \theta\right)$ a certain family of transition densities $\{p(x, t / y, s, \theta)\}$ is characterized. If a model is correctly specified, there exists some $\theta_{0} \in \Theta$

satisfying $\left\{p\left(x, t / y, s, \theta_{0}\right)=p_{0}(x, t / y, s)\right\}$ almost everywhere for some $\theta_{0} \in \Theta$. To test such a hypothesis, Hong and $\mathrm{Li}(2005)$ first transform the discredited data $\left\{X_{\tau \Delta}\right\}_{\tau=1}^{n}$ via a probability integral transform and define this discrete transformed sequence by

$$
Z_{\tau}(\theta) \equiv \int_{-\infty}^{X_{\tau \Delta}} p\left[x, \tau \Delta / X_{(\tau-1) \Delta},(\tau-1) \Delta, \theta\right] d x, \tau=1,2, \cdots \cdots, n \cdots
$$

if the model is correctly specified, the exists some $\theta_{0} \in \Theta$ such that

$$
p\left[x, \tau \Delta / X_{(\tau-1) \triangle},(\tau-1) \triangle, \theta_{0}\right]=p_{0}\left[x, \tau \Delta / X_{(\tau-1) \Delta},(\tau-1) \triangle\right] \text { Almost surely }
$$
for all $\triangle>0$.

Consequently, the transformed series $\left\{Z_{\tau} \equiv Z_{\tau}\left(\theta_{0}\right)\right\}_{\tau=1}^{n}$ is i.i.d. $\mathrm{U}[0,1]$ under correct specification. We call $\left\{Z_{\tau}(\theta)\right\}_{\tau=1}^{n}$ "generalized residuals" of the model $\{p(x, t / y, s, \theta)\}$. Here, i.i.d. U $[0,1]$ property captures two important aspects of model specification; i.i.d. characterizes the correct specification of model dynamics and U[0,1] characterizes correct specification of the model marginal distribution.

The test that whether, $\left\{Z_{\tau}(\theta)\right\}_{\tau=1}^{n}$ follows i.i.d. $\mathrm{U}[0,1]$ is not a trivial task, because it is a joint hypothesis. The well-known Kolmogorov-Smirnov test checks $U[0,1]$ under the i.i.d. assumption rather than test i.i.d. and $U[0,1]$ jointly. It would miss the alternatives whose marginal distribution is uniform but not i.i.d. To make such joint hypothesis tests, Hong and Li (2005) develop two nonparametric tests of i.i.d. $\mathrm{U}[0,1]$ by comparing a kernel estimator $\hat{g}_{j}\left(z_{1}, z_{2}\right)$ for the joint density $\hat{g}_{j}\left(z_{1}, z_{2}\right)$ of $\left\{Z_{\tau}, Z_{\tau-j}\right\}$ with unity, the 
product of two $\mathrm{U}[0,1]$ densities.

The kernel joint density estimator is for any integer $j>0$.

$$
\begin{aligned}
& \widehat{g_{j}}\left(z_{1}, z_{2}\right)=(n=j)^{-1} \sum_{\tau=j+1}^{n} K_{h}\left(z_{1}, \widehat{Z_{\tau}}\right) K_{h}\left(z_{1}, \widehat{Z_{\tau-j}}\right) \\
& \text { Where } K_{h}(x, y)=\left\{\begin{array}{l}
h^{-1} k\left(\frac{x-y}{h}\right) / \int_{-(x / h)}^{1} k(u) d u, x \in[0, h] \\
h^{-1} k\left(\frac{x-y}{h}\right), x \in[h, 1-h]
\end{array}\right. \\
& \left\{h^{-1} k\left(\frac{x-y}{h}\right), x \in[h, 1-h]\right. \\
& h^{-1} k\left(\frac{x-y}{h}\right) / \int_{-1}^{(1-x) / h} k(u) d u, x \in[1-h, 1]
\end{aligned}
$$

And the kernel $k($.$) is a bounded symmetric probability density with support [-1,1]$ so that $\int_{-1}^{1} k(u) d u=1, \int_{-1}^{1} u k(u) d u=0$ and $\int_{-1}^{1} u^{2} k(u) d u<\infty$ One choice is the quartic kernel:

$$
k(u)=\frac{15}{16}\left(1-u^{2}\right) \sum_{i=1}^{n} X_{1}^{2} 1(|u| \leq 1)
$$

where $1(|u| \leq 1)$ is the indicator function, taking value 1 if $|u| \leq 1$ and value zero otherwise.

$\hat{Z}_{\tau}=Z_{\tau}(\hat{\theta})$ and $\hat{\theta}$ is a $\sqrt{n}$-consistent estimator for $\theta_{0}$. Like Scott (1992), $h=\widehat{S}_{z} n^{-1 / 6}$

where $\widehat{S}_{z}$ is the sample standard deviation of $\left\{Z_{\tau}\right\}_{\tau=1}^{n}$. The first tests is based on a quadratic form between $\widehat{g_{j}}\left(z_{1}, z_{2}\right)$ and 1 , the product of two $\mathrm{U}[0,1]$ densities,

$$
\widehat{M}_{1}(j) \equiv \int_{0}^{1} \int_{0}^{1}\left[\hat{g}_{j}\left(z_{1}, z_{2}\right)-1\right]^{2} d z_{1} d z_{2}
$$

and the first test statistic is a properly centered and scaled version of $\widehat{M}_{1}(j)$ :

$$
\hat{Q}(j) \equiv\left[(n-1) h \widehat{M}_{1}(j)-A_{h}^{0}\right] / V_{0}^{1 / 2}
$$


where the non-stochastic centering and scale factors

$$
\begin{aligned}
A_{h}^{0} & \equiv\left(h^{-1}-2\right) \int_{-1}^{1} k^{2}(u) d u+\int_{0}^{1} \int_{-1}^{b} k_{b}^{2}(u) d u d b \\
V_{0} & \equiv 2\left[\int_{-1}^{1}\left[\int_{-1}^{1} k(u+v) k(v)\right]^{2} d u\right]^{2} \ldots \ldots \ldots \ldots \ldots \ldots \ldots \ldots \ldots \ldots \ldots \ldots \ldots
\end{aligned}
$$

And $k_{b}(\cdot) \equiv k(\cdot) / \int_{-1}^{b} k(v) d v$

Under correct model specification, Hong and Li (2005, Theorem 1) has shown that

$$
\hat{Q}(j) \rightarrow N(0,1) \text { in distribution. }
$$

And under model misspecification, $\widehat{Q}(j) \rightarrow \infty$ in probability

Whenever $\left\{Z_{\tau}, Z_{\tau-1}\right\}$ are not independent or U[0,1].(Hong and Li (2005), Theorem 3).

The quadratic form test $\hat{Q}(j)$, though convenient and quite accurate when the true parameter $\theta_{0}$ was known, might be adversely affected by any imprecise estimate for $\hat{\theta}$ in finite samples. To alleviate this problem, Hong and Li (2005) propose a second test based on the square Hellinger metric,

$$
\widehat{M}_{1}(j) \equiv \int_{0}^{1} \int_{0}^{1}\left[\sqrt{\hat{g}_{j}\left(z_{1}, z_{2}\right)-1}\right]^{2} d z_{1} d z_{2}
$$

which is a quadratic form between $\sqrt{\hat{g_{j}}\left(z_{1}, z_{2}\right)}$ and $\sqrt{1.1}=1$. The associated test statistic is

$$
\widehat{H}(j) \equiv\left[4(n-j) h \widehat{M}_{2}(j)-A_{h}^{0}\right] / V_{0}^{1 / 2}
$$

where $A_{h}^{0}$ and $V_{0}$ are as in (14) and (15). Under correct model specification, this test has the same asymptotic distribution as $\hat{Q}(j)$ and is asymptotically equivalent to $\hat{Q}(j)$ in the sense that $\hat{Q}(j)-\hat{H}(j) \rightarrow 0$ in probability. Under model misspecification, we also have $\hat{H}(j) \rightarrow \infty$ as $n \rightarrow \infty$ whenever $\left\{Z_{\tau}, Z_{\tau^{-} j}\right\}$ are not independent or $\mathrm{U}[0,1]$. 
We summarize the omnibus evaluation procedures following Hong and Li (2005):

- Estimate the parameters of discrete spot rate models using maximum likelihood estimation (MLE) method to yield a $\sqrt{n}$-consistent estimator $\hat{\theta}$;

- Compute the model generalized residual $\left\{\hat{Z}_{\tau}=Z_{\tau}(\hat{\theta})\right\}_{\tau=1}^{n}$, where $Z_{\tau}(\theta)$ is given in (10);

- Compute the boundary-modified kernel joint density estimator $\hat{g_{j}}\left(z_{1}, z_{2}\right)$ in (11) for a pre-specified lag $j$, using a kernel in (11) and the bandwidth $h=\widehat{S}_{z} n^{-1 / 6}$, where $\widehat{S}_{z}$ is the sample standard deviation of the model generalized residual $\left\{\hat{Z}_{\tau}\right\}_{\tau=1}^{n}$;

- Compute the test statistics $\hat{Q}(j)$ in (13) and $\hat{H}(j)$ in (17);

- $\quad$ Compare the value of $\hat{Q}(j)$ or $\hat{H}(j)$

With the upper-tailed $\mathrm{N}(0,1)$ critical value $C_{\alpha}$ at level $\alpha$ (e.g., $\left.C_{0.05}=1.645\right)$. The upper-tailed rather than two sided $N(0,1)$ critical values is suitable since negative $\widehat{Q}(j)$ and $\hat{H}(j)$ occur only under correct model specification when $\mathrm{n}$ is sufficiently large. Both of $\hat{Q}(j)$ and $\hat{H}(j)$ diverge to $+\infty$ when $\left\{Z_{\tau}, Z_{\tau-j}\right\}$ are not independent or U[0,1] under model specification, granting the tests asymptotic unit power. Using these entire models we justify the result of the best performing exchange rate volatility model for Bangladesh foreign exchange market in next section.

\section{Data and Descriptive Statistics:}

We analyze the daily closing price index for Bangladesh foreign exchange market from January 1, 1999 to December 31, 2012. The parameter estimation method that we choose is MLE. In estimate process, the calculation method is BHHH 1 ). Take the significant difference after May 31, 2003 into consideration, we introduce dummy variables to mean, volatility which is represented by $\mu_{D}, \sigma_{D}$ respectively are 0 after May 31, 2003. It's mentionable that Bangladesh has been introduced the floating exchange rate system after May 31, 2003. The return indices for Bangladesh foreign exchange rate are taken from Bangladesh Bank and http://www.oanda.com/convert/fxhistory.

Daily returns are calculated by usin $r=\log \left(I_{t}\right)-\log \left(I_{t-1}\right) \mathrm{g}$ the following formula:

1) BHHH is a numerical optimization method from Berndt, Hall, Hall and Hausman (1974). Used in Gauss, for example.(Econterms) 
rit $=\log (\mathrm{It})-\log (\mathrm{It}-1)$,

Where $I_{t}$ is the return index at time $t$.

Some of the descriptive statistics for daily return are displayed in Table I. Mean returns of the Bangladesh foreign exchange rate (Tk/USD) is 1.13 percentages. Volatility (measured as a standard deviation) is 3.35 percentage. The returns of Bangladesh foreign exchange market are leptokurtic that is 148.28 (kurtosis for normal distribution should be positive three) and the return series also display significant skewness (4.7) (skewness for normal distribution should be zero). According to Jarque-Berra statistics normality is rejected for the return series. We report the Ljung-Box Q (12) statistics for testing that all autocorrelations up to lag 12 are jointly equal to zero. At lag 12 we reject the hypothesis of no autocorrelation at the 5\% significance level. Overall, these results clarify support the rejection of the hypothesis that Bangladesh foreign exchange market time series of daily returns are time series with independent daily values. Moreover, the statistics justify use of the GARCH specification in modeling the volatility of Bangladesh foreign exchange market.

The trend of exchange rate return (TK/USD) over the January 1, 1999 to December 31,2012 is shown below in figure I

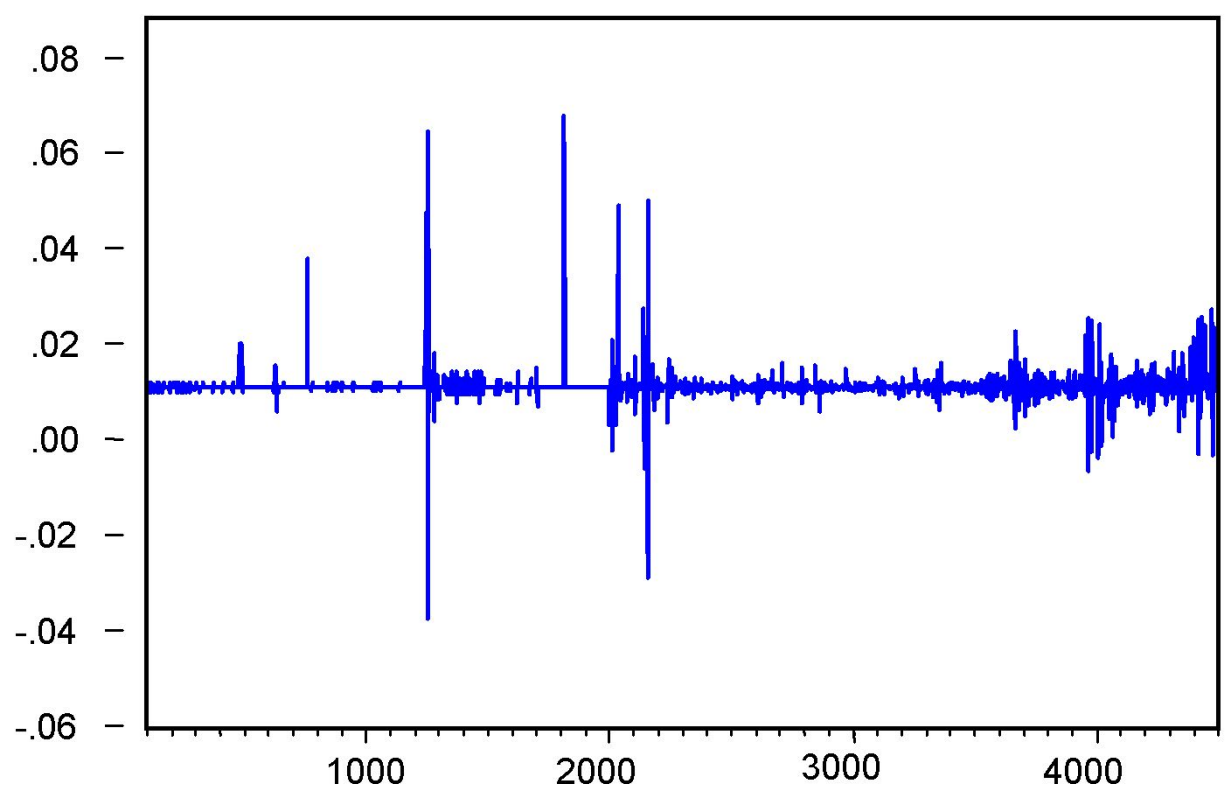

figure 1.

The Trend of Exchange Rate Return (Tk/USD) of Bangladesh 


\section{In-Sample Performance:}

Our substantial analysis is divided into two parts, (1) Estimate the parameter of various models by using Maximum Likelihood Estimation (MLE) then compare the performance of the different kind a models (2) Nonparametric specification test of various models to justify whether the model has fit well or not

\subsection{Random walk and Autoregressive (AR) model:}

Table II listed the estimate result of random walk and AR model and their t statistics as well as likelihood. Table II shows that the estimates of mean of each model are insignificant and the dummy variable is also insignificant, but the volatility and its dummy are significant it's reflecting the higher volatility after May 2003. AR Model shows that there is obvious lag 1 and lag 2 is significant and explains better return series. It is showing the autocorrelation. The log likelihood for RW is 9511 and the log likelihood of AR is 9640. However, the AR likelihood is getting bigger than RW model but its does not show that AR model perform better than RW model because adding lag variables it giving higher likelihood. However, whether the AR (2) model explains the internal regularity of return sequence better than RW model is still needed to test.

\subsection{GARCH Model:}

Estimation results of GARCH models including t-statistics as well as likelihood value are listed in Table III. The comparison of log-likelihood value with Random Walk and AR models show that adding the GARCH effect significantly improves the in-sample fit of the models. The log-likelihood increases from 9500 to more than 10200, it demonstrates that GARCH effect increase likelihood value. In Table III, all estimates of GARCH parameters are significant. The significance of $\alpha_{1}$ parameter in the model indicates the tendency of the shocks to persist. The sum of GARCH parameter estimates $\alpha_{1}+\beta$ are less than 1 which reflect that limited volatility of Bangladesh foreign exchange market. The dummy variables $\mu_{D}, \sigma_{D}$ are significantly positive and differs from zero, suggesting a higher volatility after May, 2003 


\subsection{Extensive GARCH:}

Parameter estimation results of extensive GARCH models are listed in Table IV including their $t$ statistics and likelihood value. The results show that the extended GARCH especially GARCH-M, AGARCH and IGARCH did not increase the likelihood value, even its decrease the likelihood value comparing the normal GARCH likelihood value, but comparing with RW and AR model its increase likelihood value. Table IV shows that the mean and their dummy's of all expanded GARCH are significant. The sum of GARCH parameter estimates $\alpha_{1}+\beta$ is also less than one that showing that the limited volatility of Bangladesh foreign exchange market. The result indicates that extensive GARCH is not better choice comparing the general GARCH model.

\subsection{GARCH Models with Non -normal Distribution (t-Distribution):}

The estimated parameters of GARCH models with t-distribution are listed in Table V including their $\mathrm{t}$ statistics and likelihood value. The results show that the mean and their dummy are significant except AGARCH-t. However, all GARCH models coefficient are showing significant. The sum of GARCH parameter estimates $\alpha_{1}+\beta$ is less than 1 which shows that the volatility are limited and the data is stationary, that's explain that the model are well fitted. To sum up, our in-sample discussion reveals some important stylized facts for the Bangladesh foreign exchange market volatility modeling:

Considering the GARCH can improve the in-sample fit, although some parameters are insignificant. Secondly, although it is important to model conditional heteroscedasticity through GARCH but considering the expended GARCH effect has no help on improving in sample fit. It is quite different from the estimation results in USA and other developed as well as some of developing countries as well. Thirdly, GARCH with $t$ distribution helps capture volatility clustering and especially the excess kurtosis and heavy-tails of return series. Bangladesh foreign exchange market return behaves quite differently during the period of May, 312003 to December 31, 2012. The volatility of seem significantly higher during this freely floating period. 


\section{Non Parametric Specification Test:}

To identify the best performing model in this section, we used the specification tests, we follow the test procedures of Hong and $\mathrm{Li}(2005)$ and compute the relevant $\hat{Q}(j)$ stats and picking up $\mathrm{j}$ from 1 to 20 . In this study, we only take $1,5,10$ and 15 as the value of $\mathrm{J}$ to calculate the value of $\widehat{Q}(j)$ from the each class of volatility rate models, (it's mentionable that the results of $\hat{H}(j)$ tests are quite similar). Table VI (a) reports the $\hat{Q}(j)$ test statistics as function of lag order $1,5,10,15$, for the random walk and AR models. As shown in the Table VI (a), the $\widehat{Q}(j)$ statistics for the six models range from 150 to 400 . Compared with the upper tailed $\mathrm{N}(0,1)$ critical value (e.g. 1.65 at the $5 \%$ level), the large $\widehat{Q}(j)$ statistics are overwhelmingly significant, suggesting that all six models are severely mis-specified at any reasonable significance level. There is no significant difference among the six models either specification test or comparison the log likelihood value. Therefore, these six random walk and AR models indicate that none of them can adequately capture the dynamics time-varying volatility of Bangladesh Foreign exchange market.

After adding the GARCH model into the Random walk model and AR model, the $\hat{Q}(j)$ stats of model is decreasing fast. Table VI(b) reports the $\hat{Q}(j)$ test statistics as function of lag order 1,5,10, 15 for the RW-GARCH and AR-GARCH models. The $\hat{Q}(j)$ statistics for the six models range from 147 to 250. Compared with the stats of Random walk and AR models, the adding GARCH models significantly reduce the stats, showing evidence of GARCH effect in modeling volatility return series. However, compared with the upper tailed $\mathrm{N}(0,1)$ critical value (e.g. 1.65 at the $5 \%$ level), the large $\hat{Q}(j)$ statistics are also overwhelmingly significant, suggesting that all six models are mis-specified at a reasonable significance level.

Table VI(c) reports the $\hat{Q}(j)$ test statistics as function of lag order 1,5,10, 15 for the extensive GARCH models. The $\hat{Q}(j)$ statistics for the six models range from 145 to 260 compared with the stats of GARCH models, the $\widehat{Q}(j)$ stats of extensive GARCH did not decrease, suggesting that there is not any significant difference of normal GARCH and extensive GARCH performance of model specification. However, compared with the upper tailed $\mathrm{N}(0,1)$ critical value (e.g. 1.65 at the $5 \%$ level), the large $\hat{Q}(j)$ statistics are still overwhelmingly significant and all the three specifications are refused at reasonable significance level

Finally, adding the student $\mathrm{t}$ distribution into GARCH model can reduce $\widehat{Q}(j)$ stats of GARCH significantly. Table VI(d) reports the $\widehat{Q}(j)$ test statistics as function of lag order 
1,5,10, 15 for the GARCH with $\mathrm{t}$ distribution. The $\hat{Q}(j)$ statistics for the four models range from 14 to 25 showing that $t$ distribution decrease the likelihood value dramatically although which can not pass the original premise at $1 \%$ level. Nevertheless, it can describe better characteristics of Bangladesh foreign exchange return index series. However, compared with the upper tailed $\mathrm{N}(0,1)$ critical value (e.g. 1.65 at the $5 \%$ level), the large $\hat{Q}(j)$ statistics are still overwhelmingly significant and all the three specifications are refused at reasonable significance level.

\section{Conclusion:}

Bangladesh is an emerging economy in South Asia and passing major economic change and reform during last decades. On, $31^{\text {st }}$ May 2003 Bangladesh adopted the freely floating exchange rate system. The above study reveals that after adopting freely floating the exchange rate the volatility is higher because lack of well organized foreign exchange market. However, the main objective of the paper is to find out the best performing model for estimating volatility of exchange rate for Bangladesh foreign exchange market. We applied MLE method; the models considered are RW models, ARMA models, GARCH models, Expanded GARCH models with normal as well as $t$ distribution assumption. This paper empirically investigated the daily Bangladesh foreign exchange rate dynamics using recent proposed Hong \& Li (2005) nonparametric specification test to analyze the volatility characteristic of return series and find the best performing model for Bangladesh foreign exchange dynamics. We made some conclusion as followed:

(1) AR model which is added into lag can't improve the performance and error of the model in contrast to Random Walk model. There is no significant difference between the RW and AR model. (2) Adding the GARCH effect on random walk model can improve the performance and error of the model to some extent. GARCH model which contains the leverage effect that's mean extensive GARCH model do a little help to improve the model. Even more, it can increase the specification error of the model. It means that using the Risk matrices method is inappropriate in Bangladesh foreign exchange market. (3) Adding the student $t$ distribution into GARCH model improve the better performance of model dramatically although they could not reach adequate specification for foreign exchange rate return dynamics of Bangladesh. Although the traditional likelihood comparison showed that the importance of GARCH in modeling of Bangladesh foreign exchange market dynamics, the modern nonparametric specification test found that RW, AR and the model with GARCH effect are still grossly mis-specified. All these imply that there is still a long way 
before we reach the adequate specification for exchange rate dynamics. This is for the further research.

\section{Appendix}

Table 1.

Descriptive Statistics of Daily Exchange Rate Return (Tk/USD) of Bangladesh.

\begin{tabular}{c|c|c|l|c|c|c}
\hline Sample size & $\begin{array}{c}\text { Mean } \\
(\%)\end{array}$ & $\begin{array}{c}\text { Standard } \\
\text { Deviation } \\
(\%)\end{array}$ & Skewness & Kurtosis & $\begin{array}{c}\text { Ljung-Bo } \\
\text { x stat Q } \\
(12)\end{array}$ & $\begin{array}{c}\text { Jarque-Bera } \\
(\mathrm{JB}) \text { test } \\
(\mathrm{p} \text {-value })\end{array}$ \\
\hline 4251 & 1.13 & 3.35 & 4.7 & 148.28 & 232.5 & $\begin{array}{c}1986177 \\
(0.00)\end{array}$ \\
\hline
\end{tabular}

Table 2.

MLE of RW and AR Models with Normal Distribution

\begin{tabular}{|c|c|c|c|c|c|c|}
\hline Parameters & RW & $\operatorname{AR}(1)$ & $\operatorname{AR}(2)$ & $\operatorname{AR}(3)$ & $\operatorname{AR}(4)$ & $\operatorname{AR}(5)$ \\
\hline$\mu$ & $\begin{array}{l}0.00014 \\
(1.129)\end{array}$ & $\begin{array}{c}0.0002 \\
(1.5041)\end{array}$ & $\begin{array}{l}0.00021 \\
(1.756)\end{array}$ & $\begin{array}{l}0.00022 \\
(1.7097)\end{array}$ & $\begin{array}{l}0.00021 \\
(1.6991)\end{array}$ & $\begin{array}{c}0.000217 \\
(1.7786)\end{array}$ \\
\hline$\mu_{D}$ & $\begin{array}{c}-0.00002 \\
(-0.08)\end{array}$ & $\begin{array}{c}-0.0005 \\
(-0.1006)\end{array}$ & $\begin{array}{l}-0.000018 \\
(-0.11842)\end{array}$ & $\begin{array}{c}-0.000018 \\
(-0.1176)\end{array}$ & $\begin{array}{c}-0.000017 \\
(-0.1133)\end{array}$ & $\begin{array}{r}-0.000017 \\
(-0.1140)\end{array}$ \\
\hline$\sigma$ & $\begin{array}{l}0.0032 \\
(3.555)\end{array}$ & $\begin{array}{c}0.0031 \\
(6.20)\end{array}$ & $\begin{array}{l}0.0030 \\
(7.500)\end{array}$ & $\begin{array}{l}0.0031 \\
(6.200)\end{array}$ & $\begin{array}{l}0.0031 \\
(6.200)\end{array}$ & $\begin{array}{c}0.0031 \\
(0.0005)\end{array}$ \\
\hline$\sigma_{D}$ & $\begin{array}{l}0.0005 \\
(5.00)\end{array}$ & $\begin{array}{l}0.0004 \\
(4.00)\end{array}$ & $\begin{array}{l}0.0004 \\
(4.00)\end{array}$ & $\begin{array}{l}0.0004 \\
(4.00)\end{array}$ & $\begin{array}{l}0.0004 \\
(4.00)\end{array}$ & $\begin{array}{c}0.0004 \\
(4.00)\end{array}$ \\
\hline$\phi_{1}$ & & $\begin{array}{c}-29.11 \\
(-14.42)\end{array}$ & $\begin{array}{l}-34.5191 \\
(-16.648)\end{array}$ & $\begin{array}{c}-34.2680 \\
(-16.24)\end{array}$ & $\begin{array}{c}-34.286 \\
(-16.249)\end{array}$ & $\begin{array}{l}-34.2259 \\
(-16.22) \\
\end{array}$ \\
\hline$\phi_{2}$ & & & $\begin{array}{c}-18.55 \\
(-8.954) \\
\end{array}$ & $\begin{array}{c}-18.0927 \\
(-8.233) \\
\end{array}$ & $\begin{array}{c}-17.82 \\
(-7.985)\end{array}$ & $\begin{array}{c}-17.75 \\
(-7.965) \\
\end{array}$ \\
\hline$\phi_{3}$ & & & & $\begin{array}{c}1.3462 \\
(0.635)\end{array}$ & $\begin{array}{c}1.871 \\
(0.8336)\end{array}$ & $\begin{array}{l}1.1546 \\
(0.510)\end{array}$ \\
\hline$\phi_{4}$ & & & & & $\begin{array}{c}1.4913 \\
(0.7051)\end{array}$ & $\begin{array}{c}0.1366 \\
(0.0647) \\
\end{array}$ \\
\hline$\phi_{5}$ & & & & & & $\begin{array}{c}-3.93 \\
(-1.863)\end{array}$ \\
\hline $\begin{array}{c}\text { Log } \\
\text { Likelihood }\end{array}$ & 9511.62 & 9606.31 & 9640.90 & 9636.34 & 9631.7 & 9628.58 \\
\hline
\end{tabular}

Note: The value in the prentices is the $t$ statistics. The six RW and AR models are nested by the following specification : $r_{t}=\left(\mu+\mu_{D}\right)+\sum_{i=1}^{5} \phi_{i} r_{t-1}+\left(\sigma+\sigma_{D}\right) \varepsilon_{t}, \varepsilon_{t} \sim N(0,1)$. 
Table 3.

MLE of GARCH Models with Normal Distribution

\begin{tabular}{|c|c|c|c|c|c|c|}
\hline Parameters & RW-GARCH & $\begin{array}{c}\text { AR(1)- } \\
\text { GARCH }\end{array}$ & $\begin{array}{c}\text { AR(2)- } \\
\text { GARCH }\end{array}$ & $\begin{array}{c}\text { AR(3)- } \\
\text { GARCH }\end{array}$ & $\begin{array}{c}\text { AR(4)- } \\
\text { GARCH }\end{array}$ & $\begin{array}{c}\text { AR(5)- } \\
\text { GARCH }\end{array}$ \\
\hline$\mu$ & $\begin{array}{c}0.00009 \\
(1.085)\end{array}$ & $\begin{array}{c}0.000177 \\
(1.4750)\end{array}$ & $\begin{array}{c}0.000095 \\
(1.117647)\end{array}$ & $\begin{array}{c}0.000089 \\
(1.047059)\end{array}$ & $\begin{array}{c}0.000085 \\
(1.00)\end{array}$ & $\begin{array}{c}0.000086 \\
(1.011765)\end{array}$ \\
\hline$\mu_{D}$ & $\begin{array}{l}0.00004 \\
(0.3962) \\
\end{array}$ & $\begin{array}{l}-0.000047 \\
(-0.31973)\end{array}$ & $\begin{array}{c}0.000060 \\
(0.576923)\end{array}$ & $\begin{array}{c}0.000072 \\
(0.692308)\end{array}$ & $\begin{array}{c}0.000085 \\
(0.817308)\end{array}$ & $\begin{array}{c}0.000086 \\
(0.826923) \\
\end{array}$ \\
\hline$\alpha$ & $\begin{array}{l}\text { 7.03E-07 } \\
(9.7638)\end{array}$ & $\begin{array}{c}1.8362 \text { E-05 } \\
(16.14952)\end{array}$ & $\begin{array}{c}6.45 \text { E-07 } \\
(9.485294)\end{array}$ & $\begin{array}{c}6.47 \mathrm{E}-07 \\
(9.514706) \\
\end{array}$ & $\begin{array}{c}6.48 \text { E-07 } \\
(9.529412)\end{array}$ & $\begin{array}{l}6.64 \mathrm{E}-07 \\
(9.22222)\end{array}$ \\
\hline$\alpha_{1}$ & $\begin{array}{l}0.1459 \\
(9.118)\end{array}$ & $\begin{array}{c}0.0019 \\
(6.33333)\end{array}$ & $\begin{array}{c}0.1389 \\
(9.078431)\end{array}$ & $\begin{array}{c}0.1421 \\
(9.050955)\end{array}$ & $\begin{array}{c}0.1447 \\
(8.987578)\end{array}$ & $\begin{array}{c}0.1483 \\
(8.933735)\end{array}$ \\
\hline$\beta$ & $\begin{array}{c}0.7891 \\
(62.626)\end{array}$ & $\begin{array}{c}0.9911 \\
(49.555)\end{array}$ & $\begin{array}{c}0.7938 \\
(63.504)\end{array}$ & $\begin{array}{c}0.7910 \\
(61.79688)\end{array}$ & $\begin{array}{c}0.7878 \\
(60.1374)\end{array}$ & $\begin{array}{c}0.7820 \\
(56.66667)\end{array}$ \\
\hline$\sigma_{D}$ & $\begin{array}{c}0.1959 \\
(4.3923) \\
\end{array}$ & $\begin{array}{c}0.1347 \\
(3.309582) \\
\end{array}$ & $\begin{array}{c}0.2224 \\
(4.793103) \\
\end{array}$ & $\begin{array}{c}0.2270 \\
(4.871245) \\
\end{array}$ & $\begin{array}{c}0.2333 \\
(4.96383) \\
\end{array}$ & $\begin{array}{c}0.2308 \\
(4.900212) \\
\end{array}$ \\
\hline$\phi_{1}$ & & $\begin{array}{c}-24.6238 \\
(-12.1761)\end{array}$ & $\begin{array}{c}-33.8428 \\
(-8.45901)\end{array}$ & $\begin{array}{c}-35.3575 \\
(-8.74991)\end{array}$ & $\begin{array}{c}-36.3509 \\
(-9.05806)\end{array}$ & $\begin{array}{c}-36.8727 \\
(-9.27428)\end{array}$ \\
\hline$\phi_{2}$ & & & $\begin{array}{c}-25.1080 \\
(-6.00756)\end{array}$ & $\begin{array}{c}-27.7747 \\
(-6.45308)\end{array}$ & $\begin{array}{c}-30.7187 \\
(-6.97391)\end{array}$ & $\begin{array}{c}-32.4989 \\
(-7.38376)\end{array}$ \\
\hline$\phi_{3}$ & & & & $\begin{array}{c}-12.5644 \\
(-2.85004)\end{array}$ & $\begin{array}{c}-15.6896 \\
(-3.47738) \\
\end{array}$ & $\begin{array}{c}-19.3178 \\
(-4.18143) \\
\end{array}$ \\
\hline$\phi_{4}$ & & & & & $\begin{array}{c}-11.8837 \\
(-2.58645)\end{array}$ & $\begin{array}{c}-14.9935 \\
(-3.32214)\end{array}$ \\
\hline$\phi_{5}$ & & & & & & $\begin{array}{c}-16.2222 \\
(-3.82238)\end{array}$ \\
\hline $\begin{array}{l}\text { Maximum } \\
\text { Log } \\
\text { Likelihood }\end{array}$ & 10179.2925 & 9545.5112 & 10209.98888 & 10208.84004 & 10206.81224 & 10208.5089 \\
\hline
\end{tabular}

Note: The value in the prentices is the $\mathrm{t}$ statistics; the six GARCH model are nested by the following specification : $r_{t}=\left(\mu+\mu_{D}\right)+\sum_{i=1}^{5} \phi_{i} r_{t-1}+\left(1+\sigma_{D}\right) \varepsilon_{t}, \quad \varepsilon_{t}=\sqrt{h_{t}} z_{t}, \quad h_{t}=\alpha+\alpha_{1} h_{t-1}+\beta \varepsilon_{t-1}^{2}$, $z_{t} \sim N(0,1)$. 


\section{Table 4.}

MLE of Extensive GARCH Models with Normal Distribution

\begin{tabular}{|c|c|c|c|}
\hline Parameters & RW-AGARCH & RW-IGARCH & RW-GARCH-M \\
\hline$\mu$ & $\begin{array}{c}0.000056 \\
(0.622222)\end{array}$ & $\begin{array}{c}0.000256 \\
(3.657143)\end{array}$ & $\begin{array}{l}-0.000086 \\
(-0.41148)\end{array}$ \\
\hline$\mu_{D}$ & $\begin{array}{c}0.000021 \\
(0.198113)\end{array}$ & $\begin{array}{c}0.001005 \\
(12.10843)\end{array}$ & $\begin{array}{c}0.000049 \\
(0.462264)\end{array}$ \\
\hline$\alpha$ & $\begin{array}{c}7.37 \text { E-07 } \\
(9.329114)\end{array}$ & & $\begin{array}{c}7.11 \text { E-07 } \\
(9.608108)\end{array}$ \\
\hline$\alpha_{1}$ & $\begin{array}{c}0.1196 \\
(7.035294)\end{array}$ & $\begin{array}{c}0.1617 \\
(21.27632)\end{array}$ & $\begin{array}{c}0.1463 \\
(9.086957)\end{array}$ \\
\hline$\beta$ & $\begin{array}{c}0.7847 \\
(58.12593)\end{array}$ & & $\begin{array}{c}0.7881 \\
(61.57031)\end{array}$ \\
\hline$\sigma_{D}$ & $\begin{array}{c}0.1805 \\
(4.074492)\end{array}$ & $\begin{array}{c}0.7811 \\
(15.84381)\end{array}$ & $\begin{array}{c}0.1923 \\
(4.302013)\end{array}$ \\
\hline$\alpha_{2}$ & $\begin{array}{c}0.0719 \\
(2.152695)\end{array}$ & & \\
\hline$\delta$ & & & $\begin{array}{c}0.000853 \\
(0.952009)\end{array}$ \\
\hline Log likelihood & 10181.835 & 9882.0225 & 10179.7425 \\
\hline
\end{tabular}

Note: The value in the prentices is the $\mathrm{t}$ statistics; the three Extensive GARCH models are nested by the following specification : $r_{t}=\left(\mu+\mu_{D}\right)+\left(1+\sigma_{D}\right) \varepsilon_{t}, \varepsilon_{t}$ Follow the GARCH process with normal distribution 
Table 5.

MLE for Extensive GARCH Models with Non-Nomal Distribution ( $\mathrm{t}$ - distribution)

\begin{tabular}{|c|c|c|c|c|}
\hline Parameters & RW-GARCH-t & RW-GARCH-M-t & RW-IGARCH-t & RW-AGARCH-t \\
\hline$\mu$ & $\begin{array}{c}0.000120 \\
(3.157895)\end{array}$ & $\begin{array}{l}-0.000176 \\
(-4.29268)\end{array}$ & $\begin{array}{l}-0.001764 \\
(-10.1965)\end{array}$ & $\begin{array}{c}0.000034 \\
(0.6800)\end{array}$ \\
\hline$\mu_{D}$ & $\begin{array}{l}-0.000117 \\
(-3.07895)\end{array}$ & $\begin{array}{c}0.000175 \\
(4.268293)\end{array}$ & $\begin{array}{l}-0.000336 \\
(1.307392)\end{array}$ & $\begin{array}{c}-0.000029 \\
(-0.5800)\end{array}$ \\
\hline$\alpha$ & $\begin{array}{c}1.200 \mathrm{E}-07 \\
(8.45)\end{array}$ & $\begin{array}{c}1.500 \mathrm{E}-07 \\
(8.94)\end{array}$ & & $\begin{array}{c}2.600 \mathrm{E}-07 \\
\quad(9.59)\end{array}$ \\
\hline$\alpha_{1}$ & $\begin{array}{c}0.1776 \\
(52.23529)\end{array}$ & $\begin{array}{c}0.1637 \\
(16.370)\end{array}$ & $\begin{array}{c}0.0937 \\
(8.60)\end{array}$ & $\begin{array}{l}0.2084 \\
(20.84)\end{array}$ \\
\hline$\beta$ & $\begin{array}{c}0.6429 \\
(56.39474)\end{array}$ & $\begin{array}{c}0.6455 \\
(60.3271)\end{array}$ & & $\begin{array}{c}0.7316 \\
(187.589)\end{array}$ \\
\hline$v$ & $\begin{array}{l}3.1018 \\
(31.80)\end{array}$ & $\begin{array}{c}3.0018 \\
(39.758)\end{array}$ & $\begin{array}{c}3.975 \\
(34.217)\end{array}$ & $\begin{array}{l}3.0008 \\
(29.69)\end{array}$ \\
\hline$\alpha_{2}$ & & & & $\begin{array}{c}1.4995 \\
(52.7992)\end{array}$ \\
\hline$\delta$ & & $\begin{array}{c}0.2072 \\
(11.38462)\end{array}$ & & \\
\hline Log likelihood & 13869.2025 & 13940.775 & 12068.195 & 13526.1675 \\
\hline
\end{tabular}

Note: The value in the prentices is the $t$ statistics, the four Extensive GARCH with non-normal distribution models are nested by the following specification : $r_{t}=\left(\mu+\mu_{D}\right)+\varepsilon_{t}, \varepsilon_{t}$ Follows the GARCH process with non normal distribution

Table 6.

$\widehat{Q}(j)$ Statistics of Nonparametric Specification test for All Models

(a) RW and AR Models With Normal Distribution

\begin{tabular}{c|c|c|c|c|c|c}
\hline $\mathrm{J}$ & $\mathrm{RW}$ & $\mathrm{AR}(1)$ & $\mathrm{AR}(2)$ & $\mathrm{AR}(3)$ & $\mathrm{AR}(4)$ & $\mathrm{AR}(5)$ \\
\hline 1 & 168.13 & 391.56 & 388.11 & 391.45 & 285.62 & 400.5 \\
\hline 5 & 153.59 & 377.19 & 372.85 & 370.46 & 275.45 & 384.40 \\
\hline 10 & 158.45 & 367.89 & 339.50 & 360.40 & 264.74 & 373.56 \\
\hline 15 & 150.12 & 366.54 & 361.23 & 358.53 & 273.20 & 374.50 \\
\hline
\end{tabular}




\section{Table 6.}

$\widehat{Q}(j)$ Statistics of Nonparametric Specification test for All Models

(b) GARCH Models with Normal Distribution

\begin{tabular}{c|c|c|c|c|c|c}
\hline$J$ & RW-GARCH & $\begin{array}{c}\text { AR(1)- } \\
\text { GARCH }\end{array}$ & $\begin{array}{c}\text { AR(2)- } \\
\text { GARCH }\end{array}$ & $\begin{array}{c}\text { AR(3)- } \\
\text { GARCH }\end{array}$ & $\begin{array}{c}\text { AR(4)- } \\
\text { GARCH }\end{array}$ & $\begin{array}{c}\text { AR(5)- } \\
\text { GARCH }\end{array}$ \\
\hline 1 & 155.71 & 213.50 & 245.12 & 240.22 & 273.78 & 250.45 \\
\hline 5 & 159.86 & 216.45 & 236.15 & 226.57 & 246.42 & 246.98 \\
\hline 10 & 149.11 & 217.85 & 234.26 & 224.29 & 237.00 & 244.88 \\
\hline 15 & 147.59 & 203.75 & 229.60 & 230.45 & 223.76 & 239.61 \\
\hline
\end{tabular}

\section{Table V6.}

$\hat{Q}(j)$ Statistics of Nonparametric Specification Test for All Models (continue)

(c)Extensive GARCH and with normal distribution

\begin{tabular}{c|c|c|c}
\hline $\mathrm{J}$ & RW-AGARCH & RW-IGARCH & RW-GARCH-M \\
\hline 1 & 180.62 & 274.12 & 250.713 \\
\hline 5 & 155.46 & 254.80 & 259.55 \\
\hline 10 & 147.50 & 249.01 & 249.44 \\
\hline 15 & 145.89 & 207.09 & 201.03 \\
\hline
\end{tabular}

\section{Table 6.}

$\widehat{Q}(j)$ Statistics of Nonparametric Specification Test for All Models (continue)

(d) GARCH Models with t- Distribution

\begin{tabular}{c|c|c|c|c}
\hline $\mathrm{J}$ & RW-GARCH-t & RW-AGARCH-t & RW-IGARCH-t & RW-GARCH-M-t \\
\hline 1 & 25.12 & 22.52 & 23.15 & 21.11 \\
\hline 5 & 19.45 & 23.12 & 24.15 & 17.45 \\
\hline 10 & 14.20 & 19.10 & 18.20 & 14.42 \\
\hline 15 & 20.80 & 17.59 & 22.45 & 15.80 \\
\hline
\end{tabular}




\section{Reference}

Aggarwal, R., C. Inclan and R. Leal (1997): "Volatility of Emerging Stock Markets", Journal of International Money and Finance, 16, 561-579.

Ait-Sahalia, Y.(1996): "Testing Continuous-Time Models of the Spot Interest Rate, Review of Financial Studies 9, 385-426.

Box, G. E. P. and G. M. Jenkins, (1970): "Time Series Analysis Forecasting and Control". San Francisco: Holden-Day

Diebold, F. X., T. A. Gunther and A. S. Tay (1998): "Evaluating Density Forecasts With Applications to Financial Risk Management," International Economic Review 39, 863-883

Franses, P.H. and R. Van Dijk (1996): "Forecasting Stock Market Volatility using (non-linear) GARCH models" Journal of Forecasting, Vol. 15, Pp 229-235

Gallant, A.R. and G. Tauchen(1996): "Which Moments to Match?", Econometric Theory $12,657-681$.

Hong, Y. and H. Li. (2005): "Nonparametric Specification Testing for Continuous-Time Models With Applications to Interest Rate Term Structures", The Review of Financial Studies, 18 (1):37-84.

Hong, Y., H. Li and F. Zhao (2004): "Out-of-Sample Performance of Discrete-Time Spot Interest Rate Models", Journal of Business \& Economics Statistics, Forthcoming

Jorion, P., (1995): "Predicting Volatility in the Foreign Exchange Market", Journal of Finance 50, 507-528

Samuelson, P.A, (1965): "Proof that properly anticipated prices fluctuate randomly". Industrial Management Review 6, 41-50.

Santana, E. (1995): "Quadratic ARCH models" Review of Economic Studies, Vol. 62, Pp 636-661 
Schert, G.W. and P.J. Seguin. (1990): "Heteroskedasticity in Stock Returns". Journal of Finance. Vol .4. Pp. 1129-1155.

$\mathrm{Xu}, \mathrm{X}$. and S.J. Taylor, (1995): "Conditional volatility and the informational efficiency of the PHLX currency options markets. Journal of Banking and Finance 19, 803-821. 